\title{
Subsequent entry biologics - opportunities and challenges
}

\author{
Subrata Ghosh MBBS MD FRCPC FRCP FRCPE, Editor-in-Chief
}

$\mathrm{C}^{\mathrm{m}}$ urrently, infliximab and adalimumab are the two antitumour necrosis factor (TNF) agents available in Canada for the treatment of Crohn disease and ulcerative colitis (adalimumab is not yet licensed for use in ulcerative colitis). At least one more anti-TNF monoclonal antibody (golimumab) is awaiting approval. Furthermore, the gut-specific antiadhesion antibody vedolizumab is also on the horizon for inflammatory bowel disease (IBD).

Subsequent entry biologics (SEBs), also known as biosimilars, are monoclonal antibodies that are similar but not identical to the reference biologic drug (RBD). With the patents for anti-TNF antibodies, such as infliximab, coming to an end, anti-TNF SEBs have been manufactured and an important overview of this has been provided by Devlin et al (1) (pages 567-571) in the current issue of the Journal. Given the cost of biological drugs, the potential for SEBs to lower cost, both by virtue of lower cost of SEBs and competitive lowering of cost of RBDs, will be welcome. SEBs are already on the market in some geographical jurisdictions, such as South Korea, and are well on the way to approval in Europe. There are, however, certain considerations that may be of clinical relevance to practising gastroenterologists in Canada, which include the following:

- Are the molecular structures of SEBs and RBDs comparable?: Subtle differences in structure, such as fucosylated forms, may affect antibody-dependent cell-mediated cytotoxicity and binding to $F c \gamma R$, which may affect drug clearance and serum drug levels. Therefore, SEBs cannot be viewed as a generic RBD (2). It is also not clear whether the 'molecular drift' between SEBs and RBDs may widen over time as part of the manufacturing process.

- Are the pharmacokinetics of SEBs and RBDs comparable?: RBDs are used in combination with methotrexate in rheumatoid arthritis, as monotherapy in ankylosing spondylitis, and often in psoriasis and in combination with azathioprine in IBD. The doses are different for different indications in the case of RBDs. Therefore, comprehensive pharmacokinetic studies at low and high dose levels, as well as single and multiple doses, may be required to ensure the comparability of SEBs and RBDs. Serum drug levels are critical for the efficacy of monoclonal antibodies in immunemediated inflammatory diseases (3).

- Are trial designs sufficiently robust to test efficacy comparability of SEBs and RBDs?: Equivalency studies with sufficiently narrow comparability margins to establish efficacy may require very large studies, which are difficult to conduct, and would compete for the same patients who may otherwise enter studies for the development of novel compounds for the treatment of IBD. For logistical reasons, such very large equivalence studies may not be performed.

- Are the immunogenicities of SEBs and RBDs comparable?: Immunogenicity of biological drugs is an important consideration and depends on the molecular structure of the monoclonal antibody, concomitant drugs such as methotrexate or azathioprine, the nature of the immune-mediated inflammatory disease, as well as the assay platform and test method. The assay methodology should be capable of detecting unique antidrug antibody to SEB; otherwise, the immunogenicity may be underestimated. It will also be important to determine clearly whether the antidrug antibodies cross-react between RBDs and SEBs.

- Can SEB drugs be extrapolated from one indication to another?: The precise mechanism of action, site of action, dose of monoclonal antibody and safety profile may have subtle differences among different immune-mediated inflammatory diseases. Therefore, extrapolation of efficacy based on clinical trials for one indication, such as rheumatoid arthritis, to another indication, such as ulcerative colitis or Crohn disease, may be difficult. On the other hand, conducting large separate clinical trials in different immunemediated inflammatory diseases may be extremely expensive.

- Will the logistical support for administration be similar between RBDs and SEBs?: In Canada, gastroenterologists rely heavily on a support network from the sponsor company for administration of intravenous monoclonal antibodies. The comparability of such support networks between SEBs and RBDs will be important to practising gastroenterologists.

Gastroenterologists treating IBD need to watch this rapidly evolving area with interest. Any reduction in cost of treatment with monoclonal antibodies will be welcome. The unique way in which the SEB drugs will have to considered, as described by Devlin et al (1) is, however, alien to gastroenterologists who have previously considered generic 5-aminosalicylates in their practice. A basic understanding of the issues will ensure that gastroenterologists are prepared for SEBs. Switching a well-controlled patient on a biological drug to another biological drug of the same class may be inadvisable based on the experience of the SWITCH study, which switched well-controlled patients on infliximab to adalimumab (4).

\section{REFERENCES}

1. Devlin SM, Bressler B, Berstein CN, et al. Overview of subsequent entry biologics for the management of inflammatory bowel disease and Canadian Association of Gastroenterology position statement on subsequent entry biologics. Can J Gastroenterol 2013;27:567-71.

2. Health Products and Food Branch, Health Canada. Guidance for Sponsors: Information and Submission Requirements for Subsequent Entry Biologics (SEBs). 2010. <www.hc-sc.gc.ca/dhpmps/alt_formats/pdf/brgtherap/applic-demande/guides/seb-pbu/sebpbu-2010-eng.pdf> (Accessed July 10, 2013).

3. Khanna R, Sattin BD, Afif W, et al. Review article: A clinician's guide for therapeutic drug monitoring of infliximab in inflammatory bowel disease. Aliment Pharmacol Ther 2013;38:447-59.

4. Van Assche G, Vermeire S, Ballet V, et al. Switch to adalimumab in patients with Crohn's disease controlled by maintenance infliximab: Prospective randomised SWITCH trial. Gut 2012;61:229-34. 


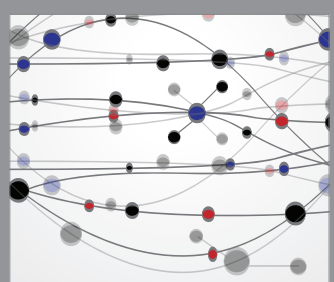

The Scientific World Journal
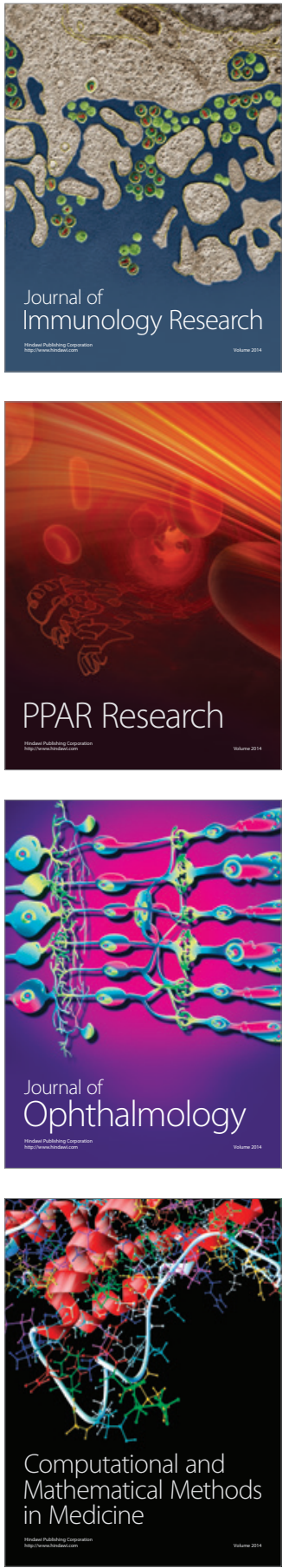

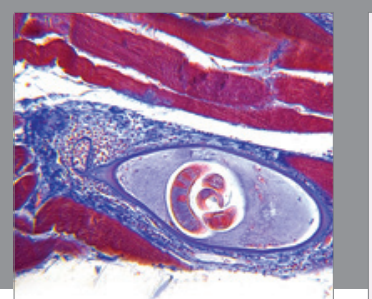

Gastroenterology Research and Practice

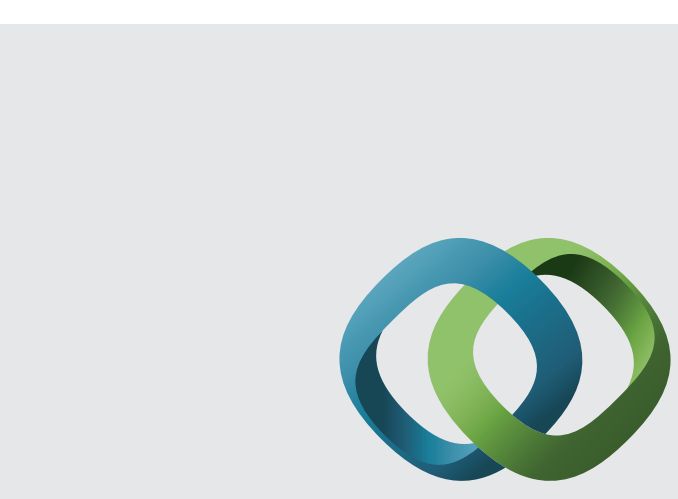

\section{Hindawi}

Submit your manuscripts at

http://www.hindawi.com
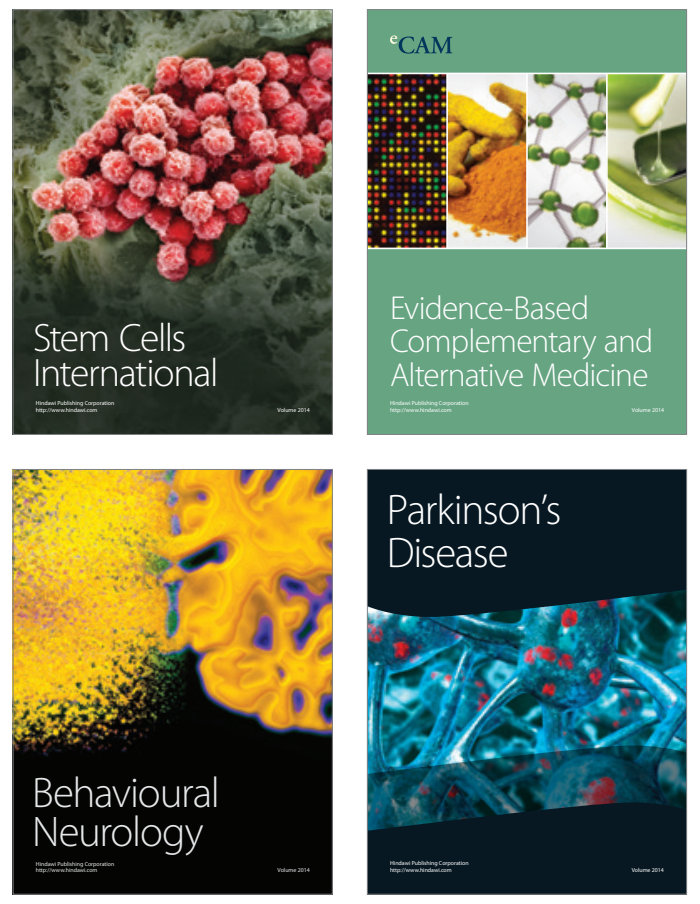
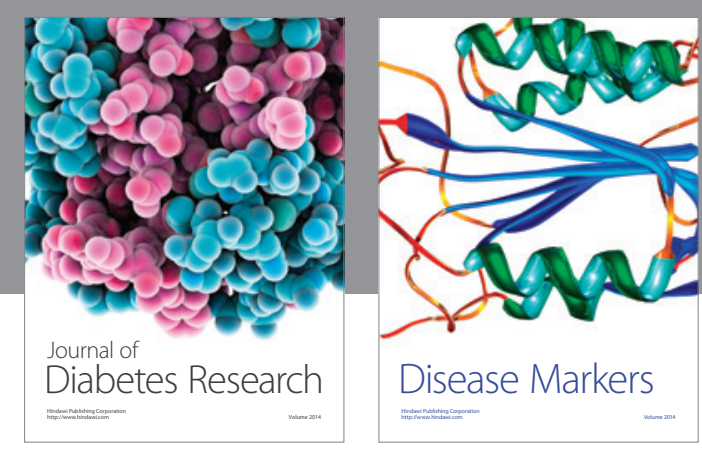

Disease Markers
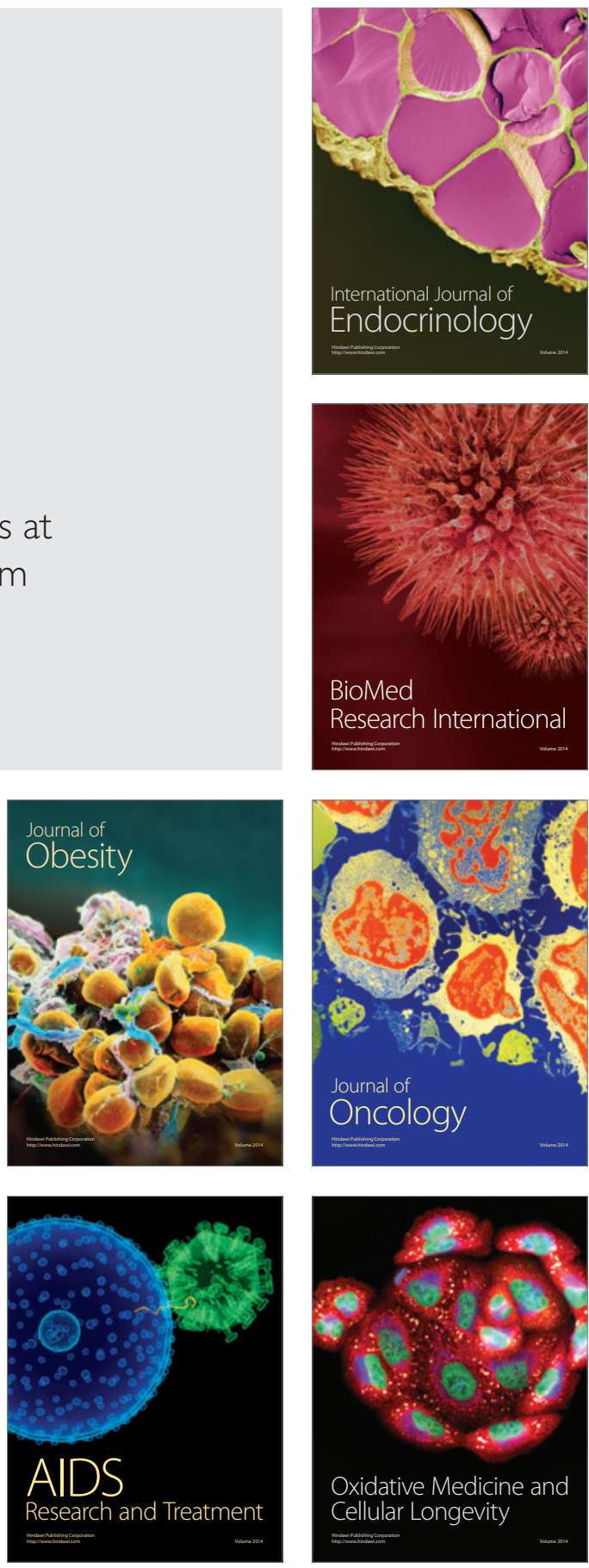